\title{
The 2005 hurricane season: An echo of the past or a harbinger of the future?
}

\author{
Jyotika I. Virmani ${ }^{1}$ and Robert H. Weisberg ${ }^{1}$ \\ Received 16 December 2005; accepted 23 January 2006; published 8 March 2006.
}

[1] Recent Atlantic hurricane activity raises several questions. For example, why was the 2005 season so early and active and are there similarities with the past? We show that parallels exist between 2005 and previously active years. Tropical Atlantic sea surface temperature (SST) anomalies beginning in winter aided the formation of early storms. On longer timescales SST, sea level pressure and zonal winds exhibit multidecadal variability; weaker easterlies during the positive phase of the Atlantic Multidecadal Oscillation (AMO) result (via oceanatmosphere interactions) in warmer water and increased hurricane activity. However, individual active years appear independent of the AMO phase. Citation: Virmani, J. I., and R. H. Weisberg (2006), The 2005 hurricane season: An echo of the past or a harbinger of the future?, Geophys. Res. Lett., 33, L05707, doi:10.1029/2005GL025517.

\section{Introduction}

[2] The 2005 hurricane season saw an unprecedented number of named tropical storms since records began in 1851. This season follows on the heels of the unusual 2004 hurricane season when, in addition to the first South Atlantic hurricane, a record-breaking number of major hurricanes made landfall in the United States, also causing destruction on the Caribbean islands in their path. These two successive unusual seasons raise many questions. Why were there so many major storms so early in the 2005 season? Are the two years connected? Is this possibly in response to recent global climate change, or are there similarities with the past? We attempt to answer these questions using monthly means of atmospheric and oceanic variables from the National Center for Atmospheric Research/National Centers for Environmental Prediction (NCAR/NCEP) reanalysis.

[3] The Atlantic hurricane season is traditionally defined as June 1 to November 30. Hurricane formation in the Caribbean and Gulf of Mexico usually occurs at the start and end of the season, and in the eastern tropical Atlantic at mid-season. Peak hurricane formation occurs between August and October, with $95 \%$ of intense hurricanes (category 3 and above) forming during these months [Landsea et al., 1994]. At this time, sea surface temperatures (SST) across the tropical Atlantic, Caribbean and Gulf of Mexico exceed $28.5^{\circ} \mathrm{C}$, and surface winds are easterly. The Bermuda High is well developed over the western Atlantic, and the Inter-Tropical Convergence Zone

\footnotetext{
${ }^{1}$ College of Marine Science, University of South Florida, St. Petersburg, Florida, USA.
}

Copyright 2006 by the American Geophysical Union. 0094-8276/06/2005GL025517\$05.00 is at its northernmost position at the beginning of this time period.

\section{The Early 2005 Hurricane Season}

[4] Monthly averaged wind and SST fields for May and June of 2003, 2004 and 2005 showed warmer SSTs (greater than $27^{\circ} \mathrm{C}$ ) in the Caribbean and tropical Atlantic Ocean in late spring and early summer 2005 (all seasons being boreal) than in the previous two years (not shown). SSTs in excess of $26^{\circ} \mathrm{C}$ are required for tropical cyclogenesis [Palmen, 1948]. The SST anomalies exceeded $1^{\circ} \mathrm{C}$ in May 2005 and were almost $2^{\circ} \mathrm{C}$ warmer in June 2005 (Figure 1), and the winds, although still easterly, were anomalously westerly and weaker than normal over the tropical Atlantic and Caribbean. Previous studies have shown that a weakening of the easterly trade winds results in increased SST in the Caribbean and the tropical and sub-tropical Atlantic [Kushnir, 1994; Enfield and Mayer, 1997; Giannini et al., 2000].

[5] Monthly averaged sea level pressure (SLP) fields for May and June of 2003, 2004 and 2005 showed a weakened Bermuda/Azores High, positioned farther to the east in 2005 than in either 2003 or 2004 (not shown). The trade winds, related to the sea level pressure gradients, were correspondingly weaker in 2005, and this relationship is seen in their monthly mean anomaly fields (Figure 1). The SLP anomaly is a large scale feature over the northern tropical and subtropical Atlantic, including the Gulf of Mexico and Caribbean Sea in May and June 2005.

[6] Latent heat flux, dependent on wind speed, plays an important role in ocean cooling [Carton and Zhou, 1997]. The convention used is that negative (positive) values are a heat loss (gain) by the ocean. Monthly averaged and anomalous latent heat flux fields from May and June of 2003, 2004 and 2005 showed that the latent heat flux loss was less over the tropical Atlantic and Caribbean in 2005 than in other years (Figure 1). This decrease in latent heat loss from the ocean contributed to increased SSTs. The temperature change associated with a given heat flux anomaly may be estimated from a one-dimensional depthintegrated temperature equation:

$$
\int_{-H}^{0} \rho c_{p}\left(\frac{\partial T}{\partial t}\right) d z=Q
$$

where $T$ is the temperature, $\rho$ is the density of seawater $\left(1023.3 \mathrm{~kg} / \mathrm{m}^{3}\right), c_{p}$ is the heat capacity of water $(3998 \mathrm{~J} / \mathrm{kg} / \mathrm{K})$, $H$ is the mixed layer water depth, and $Q$ is the heat flux. Assuming a mixed layer depth of $20 \mathrm{~m}$ and a monthly mean latent heat flux anomaly of $60 \mathrm{~W} / \mathrm{m}^{2}$ (Figure 1), the resulting change in temperature is $1.9^{\circ} \mathrm{C}$. Therefore the latent heat 

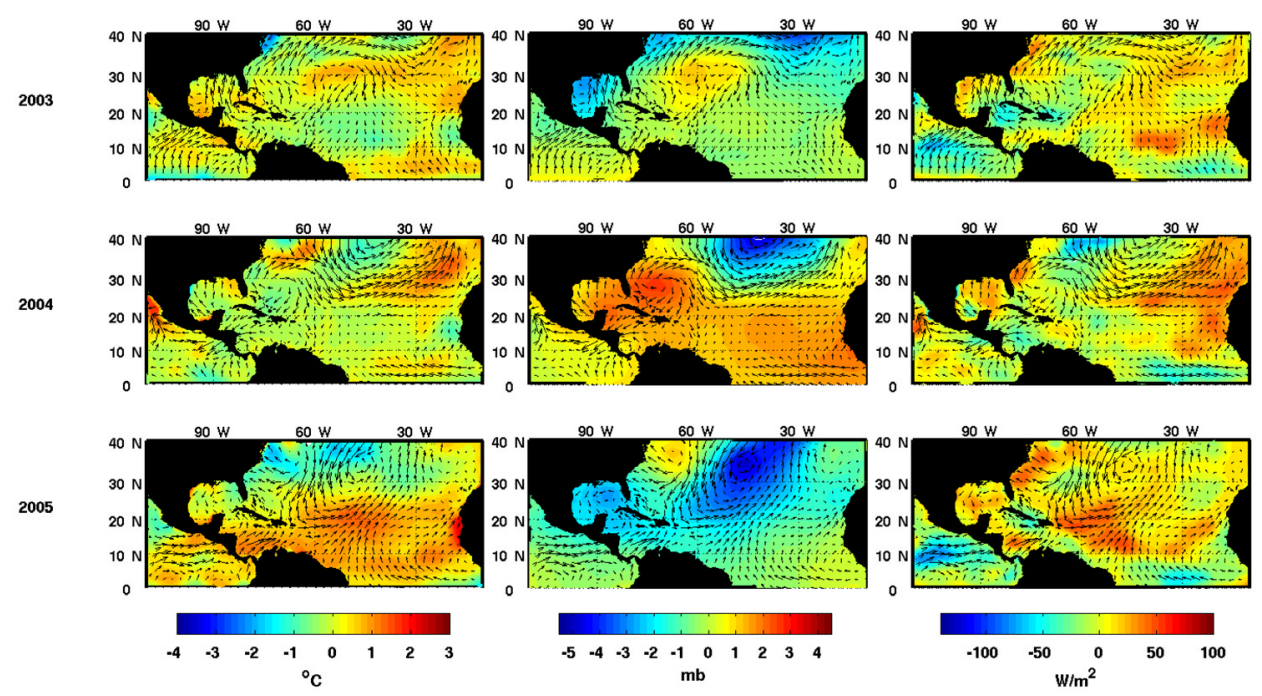

Figure 1. (left) SST, (middle) SLP, (right) latent heat flux and wind anomalies in June 2003, 2004 and 2005.

anomaly in spring and summer of 2005 was of sufficient magnitude to cause the observed SST anomaly.

\section{Comparing the Early 2005 Season With the Past}

[7] The anomalous westerly winds and warm SSTs extending eastward from the Caribbean into the tropical Atlantic observed in early summer 2005 (Figure 1) were more frequently seen during the peak of the hurricane season in September 2003-2005 (Figure 2). Additionally, the anomalously low SLP patterns in early summer 2005 (Figure 1) were also observed in the fall (Figure 2). Given the common conditions over the Caribbean and tropical Atlantic every fall and in spring/summer 2005, one may ask whether this active and intense hurricane seasons is unprecedented? A time series of SST anomalies from January 1948-June 2005, averaged over a box in the tropical Atlantic (Figure 3) shows that detrended SST anomalies exceeded $0.5^{\circ} \mathrm{C}$ during $2004-2005$, and also in 1958,1969 ,
1980, 1995 and 1998. Paralleling SST in these years, the detrended zonal wind anomalies exceeded $0.5 \mathrm{~m} / \mathrm{s}$ (Figure 4). These years also have a larger Western Hemisphere Warm Pool (WHWP0) [Wang et al., 2006]. For a separate Caribbean box SST anomalies were also greater than $0.5^{\circ} \mathrm{C}$ during 1958, 1969 and 1998 (Figure 3). Therefore conditions in the Caribbean and tropical Atlantic during the highly active 2004 and 2005 seasons were not unique during the 57 years covered by the NCEP reanalysis interval. These years of anomalously high SST and related variables have been classified as having active hurricane seasons, with 10 or more tropical storms, of which at least seven (1958), twelve (1969), nine (1980), eleven (1995) and ten (1998) were hurricanes [Staff, Weather Bureau Office, 1958; Simpson et al., 1970; Lawrence and Pelissier, 1981; Lawrence et al., 1998; Pasch et al., 2001]. The average long-term mean is 6 hurricanes per year [Pasch et al., 2001]. These years have been identified because of common conditions in the Atlantic, but they are not the only active hurricane seasons; nine out of the eleven most recent
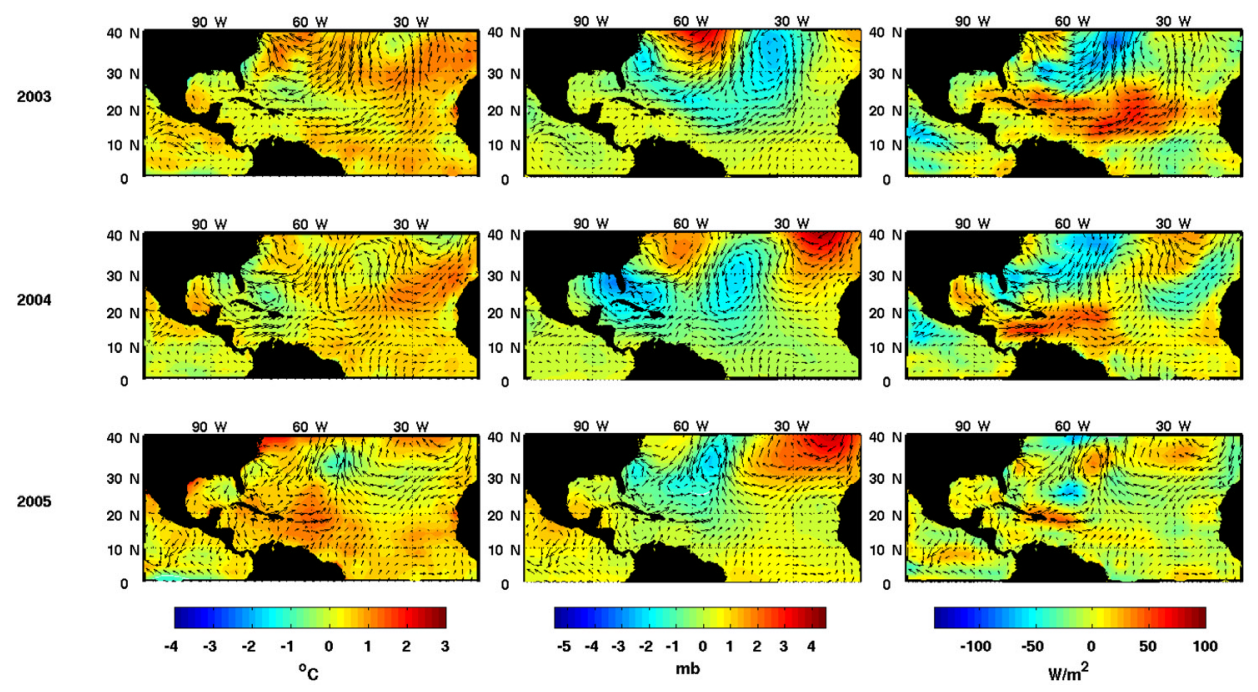

Figure 2. As for Figure 1 but in September 2003, 2004 and 2005. 


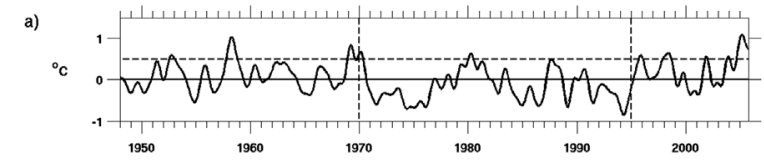

b)
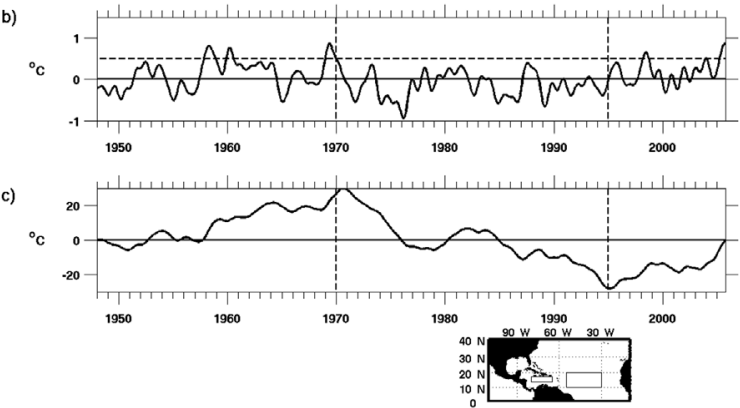

Figure 3. Detrended SST anomaly averaged over the (a) tropical Atlantic $\left(10-20^{\circ} \mathrm{N}, 30-55^{\circ} \mathrm{W}\right)$ and (b) Caribbean $\left(13.5-17.5^{\circ} \mathrm{N}, 65-80^{\circ} \mathrm{W}\right)$. (c) Integrated tropical Atlantic SST anomaly.

seasons have had above-average hurricane activity and other factors are also important in storm formation [Landsea et al., 1994].

[8] Statistically, less than $2 \%$ of intense hurricanes occur in June and July [Landsea et al., 1994]. By August 2005, seven tropical storms (two major hurricanes) had already formed, the prelude to a prolific year. The unusual aspect of the 2004-2005 seasons was that the SST anomaly was continuously higher than $0.5^{\circ} \mathrm{C}$ from August 2004 to November 2005 (not shown). In 1995 and 2004, a seasonal phase shift in the increase in SST anomalies in the tropical Atlantic resulted in warming later in these years than in other years. This exacerbated the summer season warming, and sustained anomalous warm SST through at least spring of the following year. Early season tropical storms formed in 1996 and 2005, and although there was one tropical storm in 1958 in June and one hurricane in June 1995, the remainder of the storms did not form until July or August for all other years. This suggests that the timing of the warming of the tropical Atlantic relative to the seasonal cycle plays a role in the formation of early season storms.

\section{Hurricanes and the Atlantic Multidecadal Oscillation}

[9] The question remains: are the recent active hurricane seasons related to natural climate variability or secular climate change? Recent studies have focused on interannual to multidecadal variability in the Atlantic [Chang et al., 1997; Delworth and Mann, 2000; Vauclair and du Penhoat, 2001] and the connection to hurricane activity [Landsea et al., 1999]. The Atlantic Multidecadal Oscillation (AMO) concerns a large scale temperature cycle in the north Atlantic [Kushnir, 1994; Enfield et al., 2001]. Figure 5 shows the AMO over the past 120 years. Without detrending, a gradual increase in temperature occurs over this time period in addition to the AMO. Whether this trend is part of a longer natural cycle or due to anthropogenic effects remains to be determined. The detrended time series reveals the positive and negative phases of the AMO. Hurricane frequency is generally greater (lower) when the AMO is in

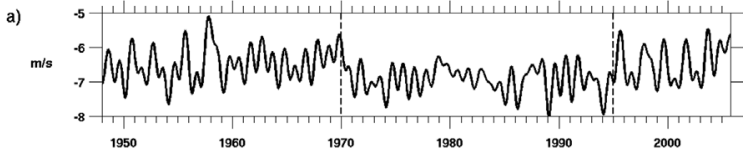

b)

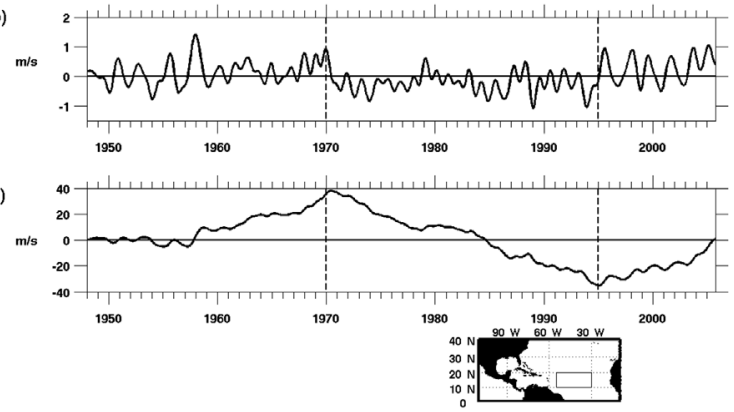

Figure 4. Zonal wind in a tropical Atlantic box: (a) average, (b) anomaly and (c) integrated anomaly.

its positive (negative) phase [Goldenberg et al., 2001]. Since the mid-1990s the AMO has been in the positive phase and hurricane activity has gradually increased. However we note that the anomalous years referred to in section 3 discriminate neither on the AMO nor the long term trend.

[10] Returning to the tropical Atlantic box, we see a covariation between the SST (Figure 3) and zonal wind (Figure 4) anomalies. Multidecadal variability in the zonal winds corresponds with the AMO such that the easterly trade winds are stronger during the negative phase of the AMO. The cumulative sum, with time, of the area under the anomaly curve gives an integrated anomaly. Integrating the SST and wind anomalies with time shows coincident transitions on multidecadal time scales; anomalous SST cooling occurs concurrently with anomalous easterly winds. Stronger easterly trade winds are associated with greater evaporative heat loss from the ocean and cooler water temperatures. The connection between winds, surface fluxes and SST has previously been established on annual and interannual time scales [Kushnir, 1994]. Increased hurricane intensity has been connected to warmer SST [Emanuel, 2005]. Additionally, we see quasibiennial oscillations in the zonal wind anomalies that exist
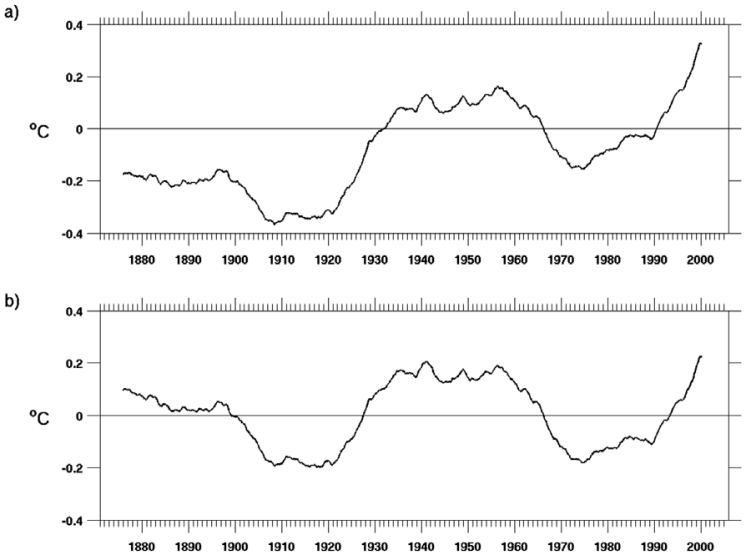

Figure 5. (a) Atlantic Multidecadal Oscillation (AMO) and (b) detrended AMO. 
prior to 1960 and after 1995, but not in the intervening period. Although multidecadal, this modulation does not correspond with the AMO. Given the various time scales of variability relative to the occurrences of active hurricane seasons there does not appear to be a simple index to which individual active hurricane seasons are connected.

\section{Conclusions}

[11] A hurricane is one way by which SSTs are adjusted back toward normal. Hurricanes cause a latent heat flow from the ocean to the atmosphere, thereby cooling the sea surface. This latent heat is then released to the upper atmosphere where the vapor condenses to rain. The latent heat loss from the tropical Atlantic and Caribbean was less in late spring and early summer 2005 than preceding years, due to anomalously weak trade winds associated with weaker SLP. This resulted in anomalously high SSTs. These factors contributed to earlier and more intense hurricanes in 2005. Similar conditions in the tropical Atlantic were seen in fall, also a time of active hurricane formation. While anomalous, these conditions in the Atlantic and Caribbean during 2004 and 2005 were not unprecedented and were equally favorable during the active hurricane seasons of 1958, 1969, 1980, 1995 and 1998.

[12] The 2004 and early 2005 active hurricane seasons are connected. The warm SST anomaly that developed in fall 2004 in the Atlantic did not decrease and therefore the tropical Atlantic SSTs were unusually warm by spring 2005, favoring the formation of intense hurricanes earlier than previously recorded. The warm SST anomaly persisted through November 2005.

[13] On multidecadal timescales, a change in the zonal winds corresponding to the AMO is observed such that the easterly trade winds are generally stronger (weaker) during the negative (positive) phase of the AMO when the SST is cooler (warmer) and the hurricane activity is generally lower (greater). While multidecadal oscillations in SST and SLP have been established in the Atlantic [Deser and Blackmon, 1993; Halliwell, 1997; Enfield and MestazNunez, 1999] and connected to the frequency of hurricanes [Landsea et al., 1999; Goldenberg et al., 2001] there is not a clear link between the AMO or the long term trend and individual active hurricane years, confirming the importance of other factors in hurricane formation.

[14] Acknowledgments. Funding was provided by the NOAA Office of Global Programs Grant NA16GP1571 and Grant N00014-02-1-0972. The second of these, for the Southeast Atlantic Coastal Ocean Observing System (SEACOOS), is administered by UNC under task order 3-1211010. Discussions with D. Mayer were useful. NCEP reanalysis and AMO time series data obtained from the NOAA-CIRES Climate Diagnostics Center, Boulder, Colorado, USA from their web-site at http:// www.cdc.noaa.gov/. The authors would like to thank the reviewers for their useful comments.

\section{References}

Carton, J. A., and Z. Zhou (1997), Annual cycle of sea surface temperature in the tropical Atlantic Ocean, J. Geophys. Res., 102, 27,813-27,824.

Chang, P., L. Ji, and H. Li (1997), A decadal climate variation in the tropical Atlantic Ocean from thermodynamic air-sea interactions, Nature, $385,516-518$.

Delworth, T. L., and M. E. Mann (2000), Observed and simulated multidecadal variability in the Northern Hemisphere, Clim. Dyn., 16, 661676.

Deser, C., and M. L. Blackmon (1993), Surface climate variations over the North Atlantic Ocean during winter: 1900-1989, J. Clim., 6, $1743-$ 1753

Emanuel, K. (2005), Increasing destructiveness of tropical cyclones over the past 30 years, Nature, 436, 686-688.

Enfield, D. B., and D. A. Mayer (1997), Tropical Atlantic sea surface temperature variability and its relation to El Nino-Southern Oscillation, J. Geophys. Res., 102, 929-945.

Enfield, D. B., and A. M. Mestaz-Nunez (1999), Multiscale variabilities in global sea surface temperatures and their relationships with tropospheric climate patterns, J. Clim., 12, 2719-2733.

Enfield, D. B., A. M. Mestaz-Nunez, and P. J. Trimble (2001), The Atlantic Multidecadal Oscillation and its relation to rainfall and river flows in the continental U.S., Geophys. Res. Lett., 28, 2077-2080.

Giannini, A., Y. Kushnir, and M. A. Cane (2000), Interannual variability of Caribbean rainfall, ENSO, and the Atlantic Ocean, J. Clim., 13, $297-$ 311 .

Goldenberg, S. B., C. W. Landsea, A. M. Mestaz-Nunez, and W. M. Gray (2001), The recent increase in Atlantic hurricane activity: Causes and implications, Science, 293, 474-479.

Halliwell, G. R., Jr. (1997), Decadal and multidecadal North Atlantic SST anomalies driven by standing and propagating basin-scale atmospheric anomalies, J. Clim., 10, 2405-2411.

Kushnir, Y. (1994), Interdecadal variations in North Atlantic sea surface temperature and associated atmospheric conditions, J. Clim., 7, 141-157.

Landsea, C. W., W. M. Gray, P. W. Miekle Jr., and K. J. Berry (1994), Seasonal forecasting of Atlantic hurricane activity, Weather, 49, $273-$ 284.

Landsea, C. W., R. A. Pielke Jr., A. M. Mestas-Nunez, and J. A. Knaff (1999), Atlantic basin hurricanes: Indices of climatic changes, Clim. Change, 42, 89-129.

Lawrence, M. B., and J. M. Pelissier (1981), Atlantic hurricane season of 1980, Mon. Weather Rev., 109, 1567-1582.

Lawrence, M. B., B. M. Mayfield, L. A. Avila, R. J. Pasch, and E. N. Rappaport (1998), Atlantic hurricane season of 1995, Mon. Weather Rev., 126, 1124-1151.

Palmen, E. (1948), On the formation and structure of tropical cyclones, Geophysics, 3, 26-28.

Pasch, R. J., L. A. Avila, and J. L. Guiney (2001), Atlantic hurricane season of 1998, Mon. Weather Rev., 129, 3085-3123.

Simpson, R. H., A. L. Sugg, and Staff (1970), The Atlantic hurricane season of 1969, Mon. Weather Rev., 98, 293-306.

Staff, Weather Bureau Office (1958), The hurricane season of 1958, Mon Weather Rev., 86, 477-485.

Vauclair, F., and Y. du Penhoat (2001), Interannual variability of the upper layer of the tropical Atlantic Ocean from in situ data between 1979 and 1999, Clim. Dyn., 17, 527-546.

Wang, C., D. B. Enfield, S.-K. Lee, and C. W. Landsea (2006), Influences of Atlantic Warm Pool on Western Hemisphere summer rainfall and Atlantic hurricanes, J. Clim., in press.

J. I. Virmani and R. H. Weisberg, College of Marine Science, University of South Florida, 140 Seventh Ave. S., St. Petersburg, FL 33701, USA. (jyotika@marine.usf.edu) 